\title{
Carbamazepine-viloxazine interaction in patients with epilepsy
}

\author{
F PISANI, A FAZIO, G OTERI, E PERUCCA, M RUSSO, R TRIO, B PISANI, \\ R DI PERRI
}

From the Institute of Neurological and Neurosurgical Sciences, University of Messina, Messina and Institute of Medical Pharmacology, University of Pavia, Pavia, Italy

SUMMARY In six depressed epileptic patients stabilised on carbamazepine therapy, addition of the antidepressant agent viloxazine $(300 \mathrm{mg} /$ day for three weeks) induced a marked (average $55 \%$ ) increase in steady-state plasma carbamazepine concentration. The concentration of the active metabolite carbamazepine-10,11-epoxide also increased during viloxazine therapy, but to a lesser extent $(16 \%)$. In three patients, these effects were associated with symptoms of carbamazepine intoxication, which regressed rapidly when plasma carbamazepine and carbamazepine-10,11epoxide levels returned to baseline values after discontinuation of viloxazine. In a seventh patient, viloxazine had to be discontinued after only two weeks because of severe side effects associated with a striking elevation of carbamazepine and carbamazepine 10,11-epoxide levels (by $197 \%$ and $137 \%$ respectively). Although viloxazine appears to be one of the few antidepressants which can be used safely in patients with epilepsy these results indicate that the drug should be prescribed with great caution in subjects treated with carbamazepine. The mechanism of the interaction probably involves inhibition of the metabolism of both carbamazepine and its active epoxide metabolite.

Viloxazine is a "second generation" antidepressant which shows anticonvulsant properties in some animal models of epilepsy. ${ }^{1}$ A number of studies, recently reviewed by Edwards, ${ }^{23}$ provide evidence that clinically the drug is non-epileptogenic or at least less epileptogenic than conventional antidepressants and therefore could be used safely in depressed epileptic patients. A rational use of viloxazine in these patients, however, requires knowledge of its possible interactions with concurrently administered anticonvulsants. $^{4}$

In a previous paper, ${ }^{5}$ we reported that the addition of viloxazine to carbamazepine therapy induces an increase in serum carbamazepine levels leading to the development of carbamazepine intoxication in some patients. The present study was designed to characterise this interaction in greater detail. To this purpose, the behaviour of the active metabolite carbamazepine-10,11-epoxide (carbamazepine E) was also investigated.

Address for reprint requests: Dr Francesco Pisani, Clinica Neurologica, Policlinico, 98013 Contesse-Messina, Italy.

Received 31 December 1985.

Accepted 21 January 1986

\section{Material and methods}

Seven hospitalised epileptic patients with depressive symptoms who had been on a constant dosage of carbamazepine for at least 2 months agreed to take part in the trial (table 1). Viloxazine was administered for 3 weeks on a thrice daily regimen $(100 \mathrm{mg}$ at $9.00,13.00$ and 18.00$)$. The dosage of $\mathrm{CBZ}$ was maintained unchanged throughout the study.

Plasma carbamazepine and carbamazepine-E levels were determined at weekly intervals before, during and after viloxazine treatment. Blood samples were collected in heparinised tubes before the first daily carbamazepine dose (9.00) and 3 hours later. The plasma was separated immediately and stored at $-20^{\circ} \mathrm{C}$ until analysis. Carbamazepine and carbamazepine-E concentrations were determined by HPLC according to Milhaly et $a l^{6}$ with minor modifications (results given in the text are means of values at the two sampling times). Plasma viloxazine levels were determined by a GLC method $^{7}$ developed in our laboratory. Plasma phenytoin levels were determined by EMIT.

Statistical analysis was carried out by means of the Student's $t$ test for paired data.

\section{Results}

Plasma drug levels Six patients completed the 3-week viloxazine treatment. In these patients, car- 
Table 1 Details of patients included in the trial

\begin{tabular}{|c|c|c|c|c|c|c|c|}
\hline Patient & Sex & Age (yr) & Weight (kg) & Seizure type* & $\begin{array}{l}\text { Seizure } \\
\text { frequency } \dagger\end{array}$ & $\begin{array}{l}\text { CBZ dosage } \\
(\mathrm{mg} / \text { day }) \ddagger\end{array}$ & Co-medication \\
\hline $\begin{array}{l}1 \\
2 \\
3 \\
4 \\
5 \\
6 \\
7\end{array}$ & $\begin{array}{l}\mathbf{M} \\
\mathbf{M} \\
\mathbf{M} \\
\mathbf{F} \\
\mathbf{F} \\
\mathbf{F} \\
\mathbf{M}\end{array}$ & $\begin{array}{l}39 \\
39 \\
48 \\
40 \\
19 \\
25 \\
33\end{array}$ & $\begin{array}{l}79 \\
80 \\
83 \\
40 \\
55 \\
60 \\
71\end{array}$ & $\begin{array}{l}\text { PC } \\
\text { PC } \\
\text { PCSG } \\
\text { PC } \\
\text { PC } \\
\text { PC } \\
\text { PCSG }\end{array}$ & $\begin{array}{r}2 \\
8 \\
6 \\
12 \\
4 \\
10 \\
2\end{array}$ & $\begin{array}{r}600 \\
800 \\
1200 \\
600 \\
600 \\
600 \\
1300\end{array}$ & 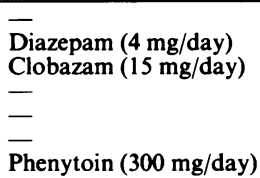 \\
\hline
\end{tabular}

* PC: partial complex; PCSG: partial complex with secondary generalization.

+ Number of seizures in the week before viloxazine.

$\$$ CBZ was taken in three divided daily doses.

Table 2 Plasma CBZ and CBZ-E concentrations $(\mu \mathrm{g} / \mathrm{ml})$ in 7 patients before, during ( + ) and after combined treatment with viloxazine ( $300 \mathrm{mg} /$ day). Values shown are means of two determinations (each in duplicate) at 9.00 (before the first CBZ dose) and three hours later.

\begin{tabular}{|c|c|c|c|c|c|c|c|c|c|c|c|c|c|c|}
\hline Patient & 1 & & 2 & & 3 & & 4 & & 5 & & 6 & & $7^{*}$ & \\
\hline $\begin{array}{l}\text { Study day } \\
1 \\
7 \\
14^{+} \\
21^{+} \\
28^{+} \\
35 \\
42\end{array}$ & $\begin{array}{l}C B Z \\
5 \cdot 3 \\
5 \cdot 2 \\
7 \cdot 3 \\
9 \cdot 0 \\
9 \cdot 2 \\
5 \cdot 5 \\
5 \cdot 0\end{array}$ & $\begin{array}{l}C B Z-E \\
0.51 \\
0.56 \\
0.57 \\
0.59 \\
0.59 \\
0.51 \\
0.53\end{array}$ & $\begin{array}{l}C B Z \\
4 \cdot 7 \\
5 \cdot 0 \\
8 \cdot 8 \\
7 \cdot 9 \\
7 \cdot 5 \\
4 \cdot 5 \\
5 \cdot 3\end{array}$ & $\begin{array}{l}C B Z-E \\
0.48 \\
0.47 \\
0.55 \\
0.52 \\
0.50 \\
0.48 \\
0.47\end{array}$ & $\begin{array}{l}C B Z \\
12.8 \\
13.6 \\
19 \cdot 3 \\
20 \cdot 4 \\
20 \cdot 8 \\
11 \cdot 8 \\
12 \cdot 2\end{array}$ & $\begin{array}{l}C B Z-E \\
1 \cdot 33 \\
1.38 \\
1.58 \\
1.66 \\
1.62 \\
1 \cdot 31 \\
1 \cdot 37\end{array}$ & $\begin{array}{c}C B Z \\
7 \cdot 6 \\
8 \cdot 1 \\
10 \cdot 9 \\
11 \cdot 2 \\
11 \cdot 7 \\
7 \cdot 2 \\
7 \cdot 6\end{array}$ & $\begin{array}{l}C B Z-E \\
0.78 \\
0.80 \\
0.86 \\
0.89 \\
0.90 \\
0.71 \\
0.74\end{array}$ & $\begin{array}{l}C B Z \\
5 \cdot 8 \\
6 \cdot 2 \\
8 \cdot 4 \\
9 \cdot 1 \\
9 \cdot 0 \\
5 \cdot 4 \\
5 \cdot 8\end{array}$ & $\begin{array}{l}C B Z-E \\
0.65 \\
0.70 \\
0.82 \\
0.78 \\
0.75 \\
0.62 \\
0.68\end{array}$ & $\begin{array}{c}C B Z \\
6.4 \\
6.8 \\
9.6 \\
10.8 \\
11 \cdot 1 \\
5.9 \\
6.2\end{array}$ & $\begin{array}{l}C B Z-E \\
0.70 \\
0.67 \\
0.81 \\
0.86 \\
0.91 \\
0.63 \\
0.65\end{array}$ & $\begin{array}{c}C B Z \\
7 \cdot 4 \\
7 \cdot 2 \\
10 \cdot 3 \\
21 \cdot 4 \\
7 \cdot 7 \\
7 \cdot 4 \\
-\end{array}$ & $\begin{array}{l}C B Z-E \\
1.67 \\
1.54 \\
1.64 \\
3.55 \\
1.95 \\
1.65 \\
-\quad\end{array}$ \\
\hline
\end{tabular}

*Viloxazine was discontinued after two weeks in this patient because of severe intoxication.

bamazepine levels increased by $55 \%$ from $7 \cdot 5 \pm 3 \cdot 2$ $\mu \mathrm{g} / \mathrm{ml}$ (mean $\pm \mathrm{SD}$ ) before viloxazine to $11.6 \pm 4.8$ $\mu \mathrm{g} / \mathrm{ml}$ after 3 weeks of viloxazine $(\mathrm{p}<0.001)$, maximal values being reached usually in the second or third week of associated treatment (table 2). Carbamazepine-E levels also increased from $0.76 \pm$ $0.32 \mu \mathrm{g} / \mathrm{ml}$ to $0.88 \pm 0.40(\mathrm{p}<0.001)$ : since this

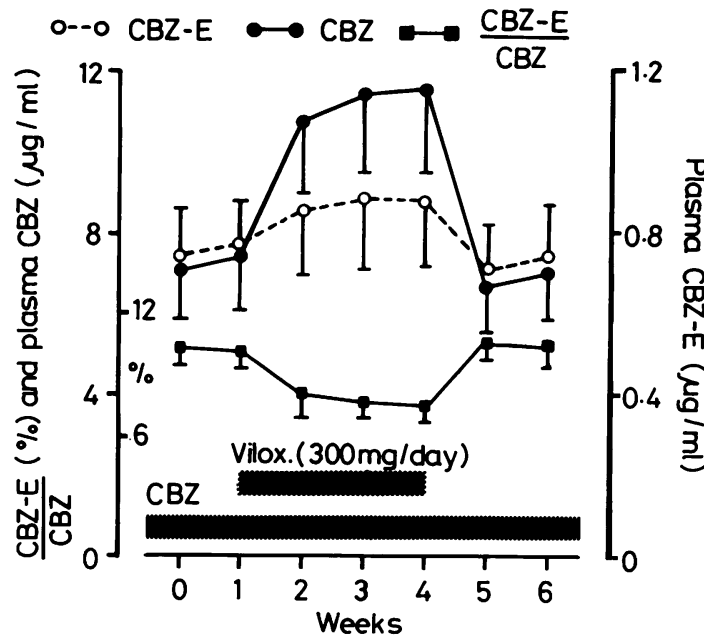

Fig 1 Effect of viloxazine treatment on plasma carbamazepine (CBZ), carbamazepine-10,11-epoxide (CBZ-E) and CBZ-E/CBZ ratio (means $\pm S D$ ) in six patients. increase was less marked than that observed for the parent drug, the carbamazepine-E/CBZ ratio declined from $0.010 \pm 0.007$ to $0.0075 \pm 0.008$, that is $25 \%$ on average ( $p<0.001$ ) (fig 1 ).

In the seventh patient, viloxazine caused a striking increase in both carbamazepine and carbamazepine-E levels (from 7.2 to 21.4 and from 1.54 to $3.65 \mu \mathrm{g} / \mathrm{ml}$, that is $197 \%$ and $137 \%$ respectively) and the antidepressant had to be discontinued after two weeks because of severe CBZ intoxication (fig 2). In this patient, the plasma levels of concurrently administered phenytoin did not show any appreciable change during viloxazine treatment (range of observed values: 12.3 to $16 \cdot 1 \mu \mathrm{g} / \mathrm{ml}$ ). In all patients, carbamazepine and carbamazepine-E levels returned to the basal (pre-viloxazine) values when the antidepressant was stopped.

Plasma viloxazine concentrations showed wide interindividual and intraindividual variations: $379 \pm$ $112 \mathrm{ng} / \mathrm{ml}$ in the first morning samples and $1726 \pm$ $574 \mathrm{ng} / \mathrm{ml}$ in the sample collected 3 hours later.

Clinical findings During viloxazine treatment patients 3, 4 and 6 developed mild symptoms consistent with carbamazepine intoxication (dizziness, drowsiness, fatigue). These symptoms disappeared rapidly after withdrawal of the antidepressant. Patient 7 developed marked drowsiness, confusion, ataxia and dizziness; the severity of these symptoms required withdrawal of this patient from the trial on the second week. 
1144

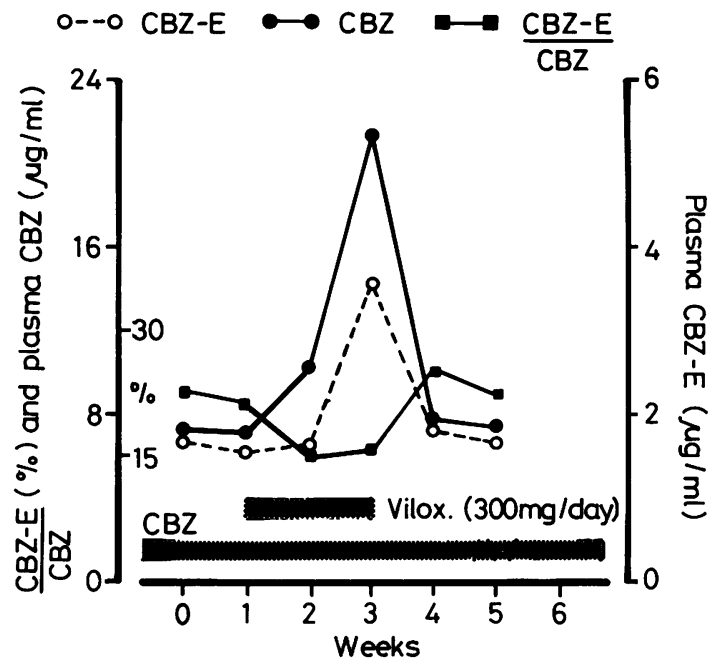

Fig 2 Effect of viloxazine treatment on plasma carbamazepine (CBZ), carbamazepine-10,11-epoxide $(C B Z-E)$ and $C B Z-E / C B Z$ ratio in patient 7 .

None of the patients showed an increase in fit frequency during the trial. A reduction in number of seizures was seen in patients 3 and 6 during viloxazine treatment. Patient 3 had six seizures in the week before viloxazine, four, three and four seizures respectively during the three weeks on viloxazine and six and five seizures respectively during the two weeks after viloxazine. In patient 6 the corresponding numbers of seizures were 10 (before viloxazine), six, four and four (during viloxazine) and nine, nine (after viloxazine).

\section{Discussion}

Although depression is a frequently encountered disorder among epileptic patients, ${ }^{8}$ its treatment may be troublesome because of the facilitating action of many antidepressant drugs on seizure activity. ${ }^{3}$ Viloxazine appears to be an atypical antidepressant in this respect because it exerts anticonvulsant effects in a number of animal models, even though at high doses a proconvulsant action may be seen. ${ }^{1}$ Available evidence from clinical studies suggests that viloxazine has a low potential for precipitating seizures in depressed subjects ${ }^{23}$ and might even improve seizure control in some epileptic patients. ${ }^{39}$ In the light of these data, an evaluation of the possible interactions with concomitantly administered antiepileptic drugs is clearly warranted.

The present study demonstrates a clinically important interaction with carbamazepine. Theoretically, all increase in plasma carbamazepine levels could result from enhancement of its oral bio-
Pisani, Fazio, Oteri, Perucca, Russo, Trio, Pisani, Perri

availability but in view of the magnitude of the interaction and the concurrent changes in metabolite levels an interference with carbamazepine elimination appears more likely. Carbamazepine is cleared almost entirely by biotransformation, the major pathways being in order of importance epoxidation to carbamazepine-E, hydroxylation of the aromatic rings and $\mathrm{N}$-glucuronidation of the carbamoyl side chain. ${ }^{10}$ Carbamazepine-E, in turn, is almost entirely converted by the enzyme epoxide hydrolase to a trans-diol derivative which is excreted in urine. Our results provide evidence that viloxazine interferes with carbamazepine metabolism in a complex way: the increase in the levels of parent drug is likely to result from inhibition of one or more of the main metabolic pathways of carbamazepine itself, while the simultaneous elevation of the levels of the metabolite almost certainly reflects a viloxazine-induced inhibition of epoxide hydrolase. In view of the possibility that the rate of formation of the epoxide was also reduced by viloxazine, the moderate elevation of plasma carbamazepine-E may well underestimate the actual degree of epoxide hydrolase inhibition. Since this enzyme plays an important role in the detoxification of reactive metabolites, ${ }^{11}$ further studies to characterise specifically the effect of viloxazine on epoxide hydrolase would be desirable.

From the clinical point of view, the interaction described in this paper has important therapeutic implications. Unless plasma carbamazepine levels are carefully monitored and carbamazepine dosage is adjusted accordingly, the rise in anticonvulsant drug levels could easily result in symptoms of intoxication. The possible contribution of the concurrent elevation of plasma CBZ-E to the side effects observed in our patients is unclear, although it should be noted that high levels of carbamazepine-E (usually above those seen in this study) have been implicated in the development of clinical toxicity in patients receiving a combination of carbamazepine and valpromide, ${ }^{1213}$ a potent inhibitor of epoxide hydrolase. ${ }^{11}$ Apart from the toxicological implications, the rise in plasma carbamazepine and carbamazepine-E levels, together with a possible anticonvulsant effect of viloxazine itself, could explain the improvement in seizure control which has been reported in some depressed epileptic patients (including two from our series) when viloxazine was added to pre-existing medication. ${ }^{39}$

In the light of the evidence presented above, frequent monitoring of plasma anticonvulsant drug levels and close clinical observation are required whenever viloxazine is prescribed in these patients.

Mrs Lorefice Carmela is thanked for her technical assistance and the Italian ICI Company for its generous financial support. 


\section{References}

${ }^{1}$ Meldrum BS, Anlerzark GM, Greenwood DT. Anticonvulsant and proconvulsant properties of viloxazine hydrochloride: pharmacological and pharmacokinetic studies in rodents and the epileptic baboon. Psychopharmacology (Berlin) 1982;76:212-7.

${ }^{2}$ Edwards JG, Glen-Bott M. Does viloxazine have epileptogenic properties? J Neurol Neurosurg Psychiatry 1984;47:960-4.

${ }^{3}$ Edwards JG. Antidepressants and seizures: epidemiological and clinical aspects. In: Trimble MR (ed). The Psychopharmacology of Epilepsy, Chichester: John Wiley 1985:119-39.

${ }^{4}$ Perucca E, Manzo L, Crema A. Pharmacokinetic interactions between antiepileptic and psychotropic drugs. In: Trimble MR (ed). The Psychopharmacology of Epilepsy, Chichester: John Wiley 1985:95-105.

${ }^{5}$ Pisani F, Narbone MC, Fazio A, Crisafulli P, Primerano G, Amendola D'agostino A, Oteri G, Di Perri R. Effect of viloxazine on serum carbamazepine levels in epileptic patients. Epilepsia 1984;25:482-5.

${ }^{6}$ Mihaly GW, Phillips JA, Louis WJ, Vajda FJ. Measurement of carbamazepine and its epoxide metabolite by high-performance liquid chromatography, and a comparison of assay techniques for the analysis of carbamazepine. Clin Chem 1977;23:2283-7.

${ }^{7}$ Fazio A, Crisafulli P, Primerano G, Amendola
D'Agostino A, Oteri G, Pisani F. A sensitive gaschromatographic assay for the determination of serum viloxazine concentration using a nitrogen-phosphorus selective detector. Therapeutic Drug Monitoring 1984;6:484-8.

${ }^{8}$ Betts TA. Depression, anxiety and epilepsy. In: Reynolds EH, Trimble MR (eds). Epilepsy and Psychiatry, Edinburgh: Churchill-Livingstone, 1981:60-71.

${ }^{9}$ Pisani F, Narbone MC, Oteri G, Primerano G, Amendola D’Agnostino A, Fazio A, Nasso C, Romano F, Di Perri $R$. Influenza della viloxazine sulla frequenza delle crisi epilettiche. Boll Lega It Epil 1985;49:231-2.

${ }^{10}$ Perucca E, Richens A. Clinical pharmacokinetics of antiepileptic drugs. In: Frey HH, Janz D (eds). Antiepileptic Drugs, Handbook of Experimental Pharmacology, Vol. 74, Berlin, Springer-Verlag 1985:661-723.

${ }^{11}$ Pacifici GM, Tomson T, Bertilsson L, Rane A. Valpromide/carbamazepine and risk of teratogenicity. Lancet 1985;ii:397-8.

${ }^{12}$ Meijer JWA, Binnie CD, Debets RMChr, Van Parys JAP, De Beer-Pawlikowski NKB. Possible hazard of valpromide-carbamazepine in epilepsy. Lancet 1984;i: 802.

${ }^{13}$ Pisani F, Fazio A, Ruello C, Gitto C, Russo F, Perucca E. Differential interactions of valproic acid and valpromide with carbamazepine in man. Proceedings 16th Epilepsy International Symposium, Hamburg September 6-9, 1985 (in press). 